\title{
Selenium-enriched exopolysaccharides produced by Enterobacter cloacae Z0206 alleviate adipose inflammation in diabetic KKAy mice through the AMPK/SirT1 pathway
}

\author{
XIHONG ZHOU, FENGQIN WANG, HANGXIAN YANG, JINGQING CHEN, YANG REN, \\ ZHANGQIN YUAN, XINXIA WANG and YIZHEN WANG \\ Key Laboratory of Animal Nutrition and Feed Science, Ministry of Agriculture, \\ Zhejiang Provincial Laboratory of Feed and Animal Nutrition, Institute of Feed Science, \\ Zhejiang University, Hangzhou, Zhejiang 310058, P.R. China
}

Received May 15, 2013; Accepted November 25, 2013

DOI: $10.3892 / \mathrm{mmr} .2013 .1859$

\begin{abstract}
Polysaccharides belong to a structurally diverse class of macromolecules, with the necessary flexibility for the precise regulatory mechanisms and high capacity for carrying biological information. On the basis of a previous study regarding the administration of selenium-enriched exopolysaccharides (Se-ECZ-EPS) produced by Enterobacter cloacae (E. cloacae) Z0206 which resulted in a reduction of blood glucose levels and showed significant anti-inflammatory and anti-diabetic effects, the present study was conducted to evaluate the effects and mechanism of EPS on the alleviation of fat inflammation in high-fat-diet (HFD) induced-diabetic KKAy mice. The HFD induced-diabetic KKAy mice were gavaged once daily with EPS $(0.2 \mathrm{mg} / \mathrm{g}$ body weight $)$ or distilled water, while the C57BL/6J mice were gavaged with distilled water. Six weeks later visceral adipose tissue (VAT) was collected for quantified polymerase chain reaction (qPCR) and western blot (WB) analysis. The results showed that following supplementation with EPS, interleukin (IL) 6, IL1 $\beta$ and tumor necrosis factor (TNF) $\alpha$ mRNA expression in VAT were significantly reduced, while Glut4, pAMPK and SirT1 protein expression were markedly increased when compared with KKAy mice gavaged with water. Furthermore, ATGL and HSL mRNA were also significantly decreased. Subsequently, 3T3-L1 adipocytes were treated with insulin to induce insulin resistance to determine the mechanism by which EPS affects
\end{abstract}

Correspondence to: Professor Yizhen Wang, Key Laboratory of Animal Nutrition and Feed Science, Ministry of Agriculture, Zhejiang Provincial Laboratory of Feed and Animal Nutrition, Institute of Feed Science, Zhejiang University, 866 Yuhangtang Road, Hangzhou, Zhejiang 310058, P.R. China

E-mail: yzwang321@zju.edu.cn

Key words: exopolysaccharides, inflammation, adenosine monophosphate activated protein, silent information regulator 1 inflammation. Following the treatment of adipocytes with $100 \mathrm{nM}$ insulin for $8 \mathrm{~h}$, IL6 and TNF $\alpha$ mRNA expression were significantly increased, while the content of glucose uptake and Glut 4 protein expression were significantly decreased. When treated with $100 \mathrm{nM}$ insulin and $0.1 \mathrm{mg} / \mathrm{ml}$ EPS, no significant change in IL6 and TNF $\alpha$ mRNA expression or glucose uptake were observed. However, when SirT1-siRNA or AMPK $\alpha 1$-siRNA was tranfected into the 3T3-L1 adipocytes prior to treatment with insulin and EPS, there was a significant increase in IL6 and TNF $\alpha$ mRNA abundance. In conclusion, VAT inflammation and lipolysis in HFD-induced KKAy mice were significantly decreased following EPS usage. Moreover, EPS may alleviate VAT inflammation primarily through the AMPK/SirT1 pathway.

\section{Introduction}

Visceral obesity and insulin resistance is associated with a chronic low-grade inflammatory state, suggesting that inflammation is a potential mechanism whereby obesity leads to insulin resistance (1). Although originally known as a passive depot for energy storage, white adipose tissue (WAT) has now been defined as a complex and active secretory organ that sends and receives signals that regulates energy expenditure, insulin sensitivity and inflammation by secreting a series of substances (2). These include tumor necrosis factor (TNF) $\alpha$, interleukin (IL) 6, leptin and adiponectin. These adipokines are expressed in visceral adipose tissue (VAT) and are associated with fasting glucose and insulin action (3). Consequently, inflammation within VAT may play a key role in the development of a number of the pathological features that results in type 2 diabetes.

Polysaccharides are members of a structurally diverse class of macromolecules, in which polymers of monosaccharide residues are joined to each other by glycosidic linkages. Polysaccharides have great potential for structural variability, as well as the necessary flexibility for the precise regulatory mechanisms of specific cell-cell interactions and the capacity for carrying biological information (4). Over recent decades, polysaccharides have been shown to exert a number 
of biological activities, including immunomodulatory (5), antitumor (6), anti-inflammatory (7) and anti-diabetic (8) activities. In addition, selenium was shown to be important in the improvement of glucose homeostasis and in the anti-inflammatory treatment $(9,10)$.

Previously, we reported that oral administration of Se-enriched exopolysaccharides (Se-ECZ-EPS) produced by Enterobacter cloacae (E. cloacae) Z0206 (11) resulted in a reduction of blood glucose and an improvement of serum insulin levels in diabetic mice (12), with EPS showing anti-inflammatory effects on broilers (13). To investigate the mechanism of the anti-diabetic effects of EPS, the experiment was designed to examine whether EPS exhibited any effects on adipose inflammation and glucose uptake in high-fat-diet (HFD)-induced diabetic KKAy mice.

\section{Materials and methods}

Materials. The Se-ECZ-EPS-producing bacterial strain E. cloacae Z0206 was identified and collected by the China General Microbiological Culture Collection Center (Beijing, China) (14).

Preparation of Se-ECZ-EPS. Preparation and purification of Se-ECZ-EPS were performed according to the previous study conducted in our laboratory (14). Cultivation medium containing $2.5 \%$ sucrose, $0.5 \%$ peptone, $0.5 \%$ yeast extract, $0.2 \% \mathrm{~K}_{2} \mathrm{HPO}_{4}, 0.1 \% \mathrm{KH}_{2} \mathrm{PO}_{4}$ and $0.05 \% \mathrm{MgSO}_{4} \bullet 7 \mathrm{H}_{2} \mathrm{O}$ was prepared. Exopolysaccharide production was performed in a $10-\mathrm{dm}^{3}$ bioreactor (Sangon Biotech Ltd., Shanghai, China) in $7 \mathrm{dm}^{3}$ growth volume with stirring rate of $200 \mathrm{rpm}$ at $30^{\circ} \mathrm{C}$ for 2 days. Concentration and time of adding selenium into culture were optimized through experiments. Aeration rate (1 vvm), growth temperature, foam level, dissolved oxygen tension (DOT) and $\mathrm{pH}$ were measured and/or controlled by the bioreactor control unit.

The fermentation liquid was centrifuged at 4,500 x g to remove mycelia. The supernatant was concentrated and precipitated with chilled $95 \% \mathrm{EtOH}$ and maintained at $4^{\circ} \mathrm{C}$ overnight. The precipitate was collected by centrifugation and freeze-dried to yield a yellow powder. Subsequently, the collected yellow powder was dissolved in $0.125 \mathrm{~mol} / 1$ solution of $\mathrm{NaOH}$ and extracted at $60^{\circ} \mathrm{C}$ for $8 \mathrm{~h}(1: 1, \mathrm{v} / \mathrm{v})$. The insoluble material was removed by centrifugation and the supernatant was added to solid ammonium sulfate until precipitation was observed (15). The suspension was allowed stand overnight at $4^{\circ} \mathrm{C}$ and centrifuged at 7,600 $\mathrm{x}$ g for $20 \mathrm{~min}$. The precipitation was collected and dissolved in water and the suspension was dialyzed against water and lyophilized to obtain Se-ECZ-EPS (EPS).

Animals. Male KKAy and C57BL/6J mice (aged, 6 weeks) were supplied by the Animal Experimental Center of Zhejiang University (Hangzhou, China). The mice were housed under a controlled environment at $22 \pm 2^{\circ} \mathrm{C}$ and relative air humidity of $60 \pm 10 \%$ under a $12-\mathrm{h}$ light/dark cycle with free access to food and water. The C57BL/6J mice were fed a normal chow diet, whereas the KKAy mice were fed a high-fat diet. The experiments were approved by the Committee of Experimental Animal Care, Zhejiang University.
Experimental design. The KKAy mice (aged, 8 weeks) were randomized into 2 groups according to fasting blood glucose values and initial body weight. Following two weeks feeding with a high-fat diet, the KKAy mice with significantly increased blood glucose level ( $\geq 20 \mathrm{mM}$ ) were gavaged once daily with distilled water or EPS $(0.2 \mathrm{mg} / \mathrm{g}$ body weight $)$. At the same time, the lean mice were also treated with distilled water. Blood glucose levels were tested regularly for the fed (tested at 8:30 a.m.) and fasted (tested at 14:30 p.m. following $5 \mathrm{~h}$ fasting) mice using a One-Touch Basic Glucose Monitor (Roche Diagnostics, Mannheim, Germany). Six weeks later, as the blood glucose of the EPS-supplemented KKAy mice steadily dropped to a level $(\leq 10 \mathrm{mM})$ similar to that of the lean mice, the animals were sacrificed following fasting for $12 \mathrm{~h}$. Visceral fat was collected and immediately frozen in liquid nitrogen and then stored at $-80^{\circ} \mathrm{C}$.

Cell culture. 3T3-L1 preadipocytes (obtained from the Chinese Academy of Medical Sciences, Beijing, China) were cultured in high glucose DMEM supplemented with $10 \%$ newborn bovine serum (growth medium) at $37^{\circ} \mathrm{C}$ in a humidified atmosphere containing $5 \% \mathrm{CO}_{2}$. Confluent cells were induced by incubation in growth medium supplemented with $1 \mu \mathrm{M}$ insulin, $0.5 \mathrm{mM}$ IBMX and $1 \mu \mathrm{M}$ dexamethasone for 3 days. The cells were then incubated in growth medium containing $1 \mu \mathrm{M}$ insulin for 3 days. The cells were subsequently maintained in growth medium until $>90 \%$ of the cells differentiated into adipocytes.

RNA interference (RNAi). Based on the complete sequences of mouse SirT1 and AMPK 1 1 (NCBI accession nos. NM_001159589.1 and NM_001013367.3), four potential small interference (siRNA) target sites were determined using the Qiagen siRNA design program. These were confirmed by BLAST for specificity. Oligonucleotides that would produce plasmid-based siRNA were cloned into pSilencer ${ }^{\mathrm{TM}}$ 4.1-CMV neo plasmids (Ambion, Austin, TX, USA) and all constructs were confirmed by sequencing. The most effective target sequence (GATGCTGTGAAGTTACTGC) of mouse SirT1 and (TATGTCTCTGGAGGAGAGC) of mouse AMPK $\alpha 1$ for RNAi (SirT1-siRNA and AMPKa1-siRNA) were screened and the RNAi conditions were optimized.

3T3-L1 adipocytes were seeded in 6-well plates. For the SirT1 and AMPK $\alpha 1$ knockdown experiments, the cells were transiently transfected with $20 \mu \mathrm{M}$ SirT1 or AMPK $\alpha 1$ siRNA or negative control siRNA using Lipofectamine ${ }^{\mathrm{TM}} 2000$ transfection reagent (Invitrogen Life Technologies, Carlsbad, CA, USA) as per the manufacturer's instructions. Following $24 \mathrm{~h}$, the protein expression of SirT1 and AMPK $\alpha 1$ were detected.

Cell treatment. 3T3-L1 adipocytes were treated with insulin to induce insulin resistance and inflammation according to a previous study (16). EPS $(0.1 \mathrm{mg} / \mathrm{ml})$ was added with $100 \mathrm{nM}$ insulin to determine the effects of EPS on insulin-induced inflammation. To confirm the effect of EPS on inflammation, SirT1-siRNA or AMPK $\alpha 1$-siRNA was tranfected into the 3T3-L1 adipocytes prior to treatment with insulin and EPS.

Glucose uptake measurement. Glucose uptake assays were performedusing the glucose analog 2-[N-(7-nitrobenz-2-oxa-1, 
3-diazol-4-yl) amino]-2-deoxy-d-glucose (2-NBDG; Cayman, Ann Arbor, MI, USA), a fluorescent indicator for direct glucose uptake, as previously described (17). Differentiated 3T3-L1 cells were treated with vehicle or EPS $(0.1 \mathrm{mg} / \mathrm{ml})$ and $100 \mathrm{nM}$ insulin in the presence or absence of $10 \mu \mathrm{M} 2-\mathrm{NBDG}$. The concentration of 2-NBDG and the time of incubation $(1 \mathrm{~h})$ were selected according to previous studies $(18,19)$. The incubation medium was then removed and cells were washed twice with PBS. The cells in each well were subsequently resuspended in $200 \mu \mathrm{l}$ pre-cold growth medium and maintained at $4{ }^{\circ} \mathrm{C}$ for further analysis performed within $1 \mathrm{~h}$. The fluorescence intensity of 2-NBDG was recorded using a FACS flow cytometer (FACSCanto ${ }^{\mathrm{TM}}$ II Flow Cytometry System; BD Biosciences, San Diego, CA, USA). To rule out false-positives, the fluorescence intensity of cells in the absence of 2-NBDG was measured and this value was considered as the background level. The relative fluorescence intensities, minus the background level, were used for data analysis.

Quantified polymerase chain reaction ( $q P C R)$. Total RNA was isolated using the TRIzol reagent (Invitrogen Life Technologies) and the RNA concentration was quantified by the NanoDrop ND-1000 spectrophotometer. A one-step qPCR assay was employed using the SYBR Premix Ex Taq ${ }^{\mathrm{TM}}$ (Takara Bio Inc., Otsu, Japan). TNF $\alpha$, IL1 $\beta$, IL6, IL10, ATGL and HSL transcripts were quantified using qPCR technology on the LightCycle1.5 (MasterCycler EP gradient RealPlex4; Eppendorf, Hamburg, Germany). The following primers were designed using Primer Premier 5.0 (from $5^{\prime}$ to $3^{\prime}$ ): TNF $\alpha$ forward, GCATGGTGGTGGTTGTTTCTGACGAT and reverse GCTTCTGTTGGACACCTGGAGACA; IL1 $\beta$ forward, CCTAGGAAACAGCAATGGTCGGGAC and reverse GTCAGAGGCAGGGAGGGAAACAC; IL6 forward, GAGTCACAGAAGGAGTGGCTAAGGA and reverse CGCACTAGGTTTGCCGAGTAGATC; IL10 forward, GGACCAGCTGGACAACATACTGCTA and reverse CCGATAAGGCTTGGCAACCCAAGT; ATGL forward, GAGCCCCGGGGTGGAACAAGAT and reverse AAAAGGTGGTGGGCAGGAGTAAGG and HSL forward, GCCGGTGACGCTGAAAGTGGT and reverse CGCGCAGATGGGAGCAAGAGGT. The PCR system consisted of $10 \mu \mathrm{l}$ of SYBR Premix Ex Taq (2X) mix, $0.4 \mu \mathrm{l}$ ROX Reference Dye (50X), 1.0 $\mu \mathrm{l}$ cDNA, $7.8 \mu \mathrm{l}$ doubled-distilled water and $0.4 \mu \mathrm{l}$ primer pairs $(10 \mathrm{mM})$, all in a total volume of $20 \mu \mathrm{l}$. PCR conditions were $95^{\circ} \mathrm{C}$ for $30 \mathrm{sec}$, followed by 40 cycles of $5 \mathrm{sec}$ at $95^{\circ} \mathrm{C}$ and $34 \mathrm{sec}$ at $60^{\circ} \mathrm{C}$. All results were normalized to the levels of $18 \mathrm{~S}$ rRNA and relative quantification was calculated using the $\Delta \Delta \mathrm{Ct}$ formula. All samples were run in triplicate and the average values were calculated.

Western blot analysis. Protein supernatants were run on $10 \%$ SDS acrylamide gels and electro-blotted onto nitrocellulose membranes (Pall, Co., Port Washington, New York, USA). The membranes were incubated with primary antibodies overnight at $4^{\circ} \mathrm{C}$, followed by incubation with anti-rabbit or anti-mouse IgG. Primary antibodies specific against GAPDH, SirT1 (Santa Cruz Biotechnology, Inc., Santa Cruz, CA, USA), AMPKa1, pAMPK 1 1 (phospho S487) (Abcam, Cambridge,
MA, USA) and Glut4 (Signalway Antibody, College Park, MD, USA) were used.

Statistical analysis. Data are presented as the mean \pm SEM. A one-way analysis of variance (ANOVA) was used to determine whether a significant difference was present among the treatment groups using SPSS 13.0 (SPSS Inc., Chicago, IL, USA). $\mathrm{P}<0.05$ was considered to indicate a statistically significant difference.

\section{Results}

Effects of a supplemented diet EPS on VAT inflammation and lipolysis of HFD-induced diabetic KKAy mice. To investigate the effects of EPS on VAT inflammation, EPS was supplemented to HFD-induced diabetic KKAy mice. There was a significant increase in IL1 $\beta$, IL6 and TNF $\alpha$ gene expression in the VAT of HFD-induced diabetic mice compared with C57BL/6J mice, while EPS supplementation significantly alleviated this increase (Fig. 1A). Compared with C57BL/6J mice, ATGL and HSL abundance in diabetic mice were significantly increased, while ATGL and HSL abundance in mice supplemented with EPS were significantly reduced compared with diabetic mice (Fig. 1B). Diabetic mice also showed a significantly reduced protein expression of Glut4, SirT1, AMPK $\alpha 1$ and pAMPK $\alpha 1$, while EPS supplementation alleviated these reductions (Fig. 1C).

Effects of EPS on insulin-induced inflammation and glucose uptake in 3T3-L1 cells. To induce insulin resistance, fully differentiated 3T3-L1 adipocytes were treated with insulin. IL6 mRNA expression was significantly increased following treatment with insulin for $8 \mathrm{~h}$ (16). EPS was observed to significantly reduce insulin-induced IL6 and TNF $\alpha$ mRNA expression (Fig. 2A) and increased glucose uptake (Fig. 2B). Moreover, treatment with insulin decreased Glut4, SirT1, AMPK $\alpha 1$ and pAMPK $\alpha 1$ protein expression, while EPS was capable of counteracting the effects of insulin (Fig. 2D).

To investigate the possible mechanisms underlying alleviation of VAT inflammation in KKAy mice by EPS supplementation, AMPK $\alpha 1$ or SirT1 were knocked down by siRNA. AMPK $\alpha 1$ protein expression was not affected by SirT1-siRNA and SirT1 protein expression was not affected by AMPK $\alpha 1$-siRNA (Fig. 2C). Following treatment with AMPK $\alpha 1-$ siRNA or SirT1-siRNA, IL6 and TNF $\alpha$, gene expression remained significantly reduced when compared with 3T3-L1 cells treated with insulin. However, IL6 and $\mathrm{TNF} \alpha$ gene expression was significantly higher than 3T3-L1 cells treated with insulin and EPS.

\section{Discussion}

Local chronic inflammation within adipose tissue may be the primary and crucial event that leads to systemic insulin resistance and systemic inflammation (1). This inflammation is claimed to be the connection between insulin resistance, obesity and diabetes (20). Our previous studies have demonstrated, that EPS has an immunomodulatory and antioxidant effect $(14,21)$ and notably, administration of EPS resulted in a reduction of blood glucose levels and showed significant 
A

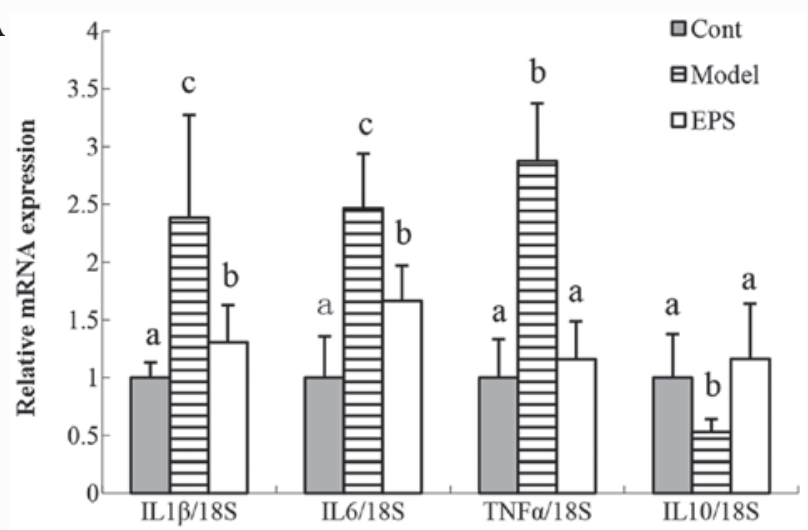

B
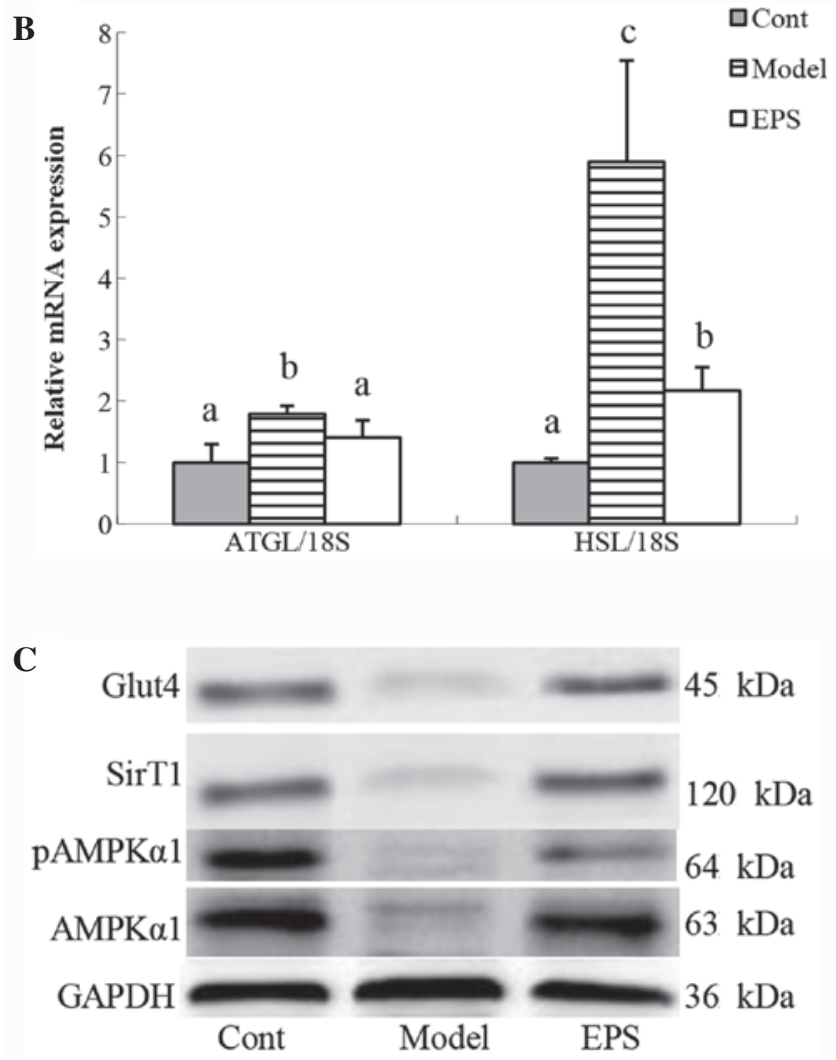

Figure 1. Effects of EPS supplemention on VAT inflammation and lipolysis of HFD-induced diabetic KKAy mice. (A) Analysis of inflammatory cytokine gene expression in VAT. (B) Analysis of two lipase gene expression in VAT. Values are expressed as mean \pm SD. (C) Analysis of protein expression using western blotting. Cont, control group; Model, HFD-induced diabetic KKAy mice; EPS, HFD-induced diabetic KKAy mice treated with EPS. EPS, exopolysaccharides; VAT, visceral adipose tissue; HFD, high-fat-diet; IL, interleukin; TNF, tumor necrosis factor.

anti-inflammatory and anti diabetic effects $(12,13)$. Thus, EPS was used as a therapeutic drug for the HFD-induced diabetes of KKAy mice in the present experiment. Notably, the results showed that VAT inflammation was significantly decreased following EPS usage. EPS may alleviate inflammation primarily through the AMPK/SirT1 pathway. The anti-inflammatory effects of Se-ECZ-EPS are hypothesized to be the cause of the anti-diabetic effects of EPS (22).

In the development of obesity, chronic over feeding and glucose intake causes hypertrophy of adipocytes and inflam-
A
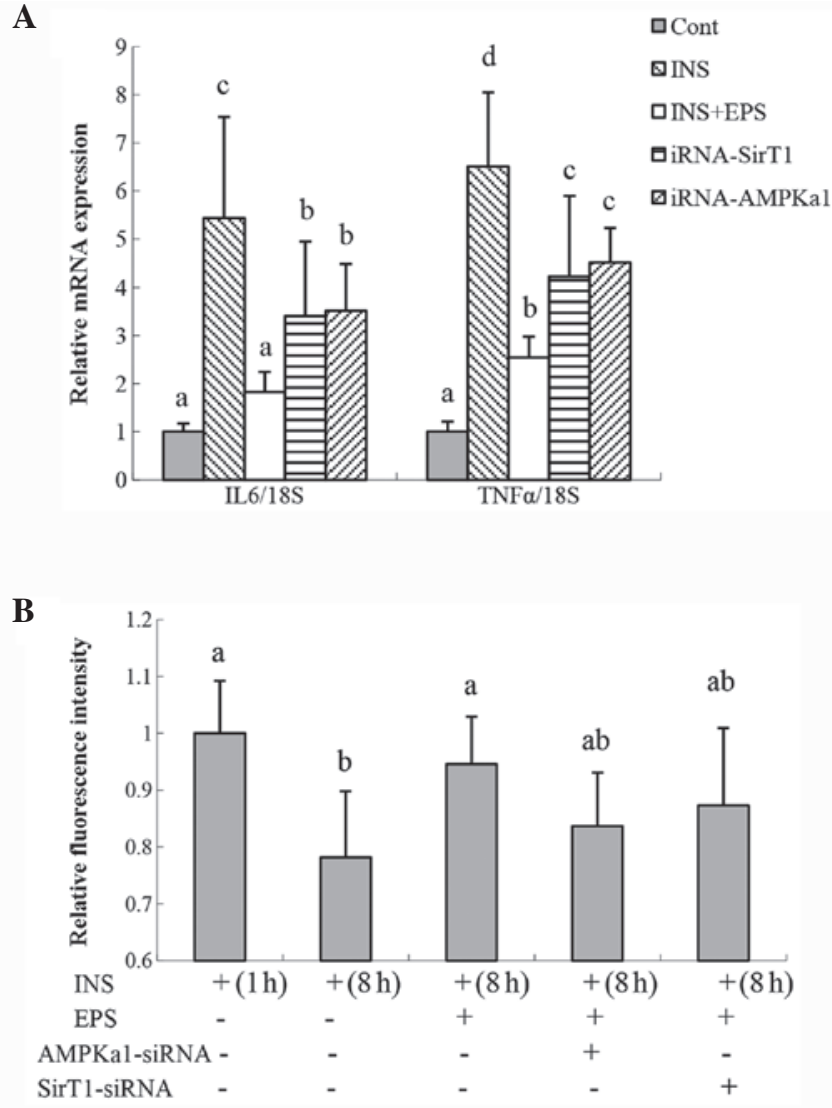

C

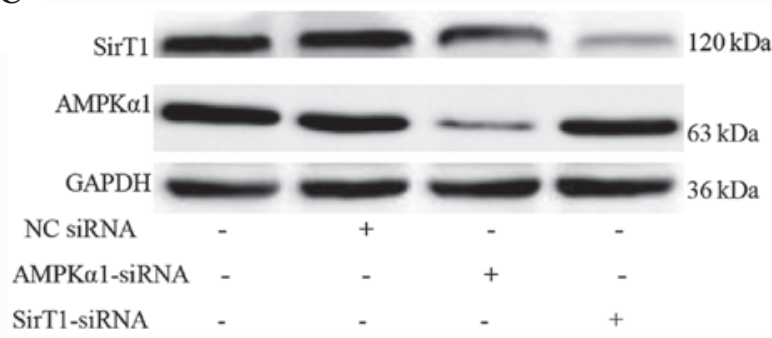

D

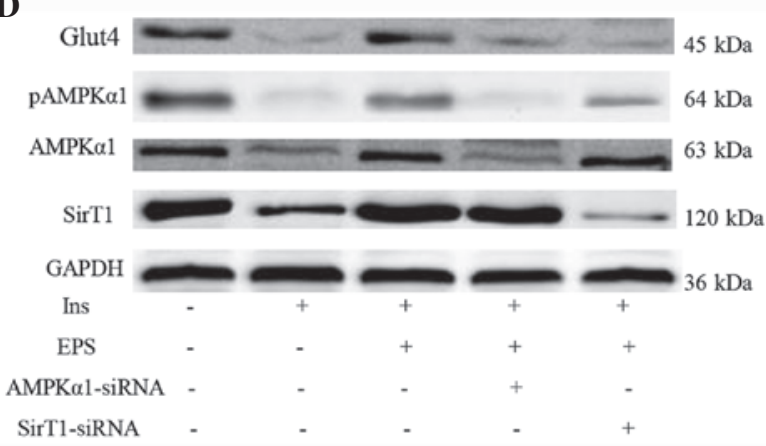

Figure 2. Effects of EPS on insulin-induced inflammation and glucose uptake in 3T3-L1 cells. (A) Analysis of proinflammatory cytokine gene expression in 3T3-L1 cells. Values are expressed as mean \pm SD. Control group; INS, cells treated with $100 \mathrm{nM}$ insulin for $8 \mathrm{~h}$; INS + EPS, cells treated with $100 \mathrm{nM}$ insulin and $0.1 \mathrm{mg} / \mathrm{ml}$ EPS for $8 \mathrm{~h}$; SirT1-siRNA, cells treated with $100 \mathrm{nM}$ insulin and EPS for $8 \mathrm{~h}$ following 16-h transfection with SirT1-siRNA; AMPK $\alpha 1$-siRNA, cells treated with $100 \mathrm{nM}$ insulin and EPS for $8 \mathrm{~h}$ following 16-h transfection with AMPK $\alpha 1$-iRNA. (B) The relative fluorescence intensities of 2-NBDG, minus the background level. 3T3-L1 cells were incubated with insulin and/or EPS for $8 \mathrm{~h}$ and $10 \mu \mathrm{M} 2-\mathrm{NBDG}$ was added for $1 \mathrm{~h}$. (C) Analysis of protein expression in 3T3-L1 cells $24 \mathrm{~h}$ following transfection. (D) Analysis of protein expression. Cells were treated with insulin and EPS for $8 \mathrm{~h}$ and AMPK $\alpha 1 /$ SirT1-siRNA for $24 \mathrm{~h}$. EPS, exopolysaccharides; INS, insulin. 
matory changes at the cellular and molecular level (23-25). TNF $\alpha$ and IL6 mRNA overexpression in adipocytes is associated with an increased concentration of circulating cytokines, which may interfere with insulin action by impairing insulin signal transduction $(20,26)$. These inflammatory signals may primarily be promoted by VAT (27), since this fat depot expands in response to chronic positive energy balance and is a more important site for IL6 and TNF $\alpha$ secretion than subcutaneous fat $(1,28)$.

Insulin resistance results in a high concentration of free fatty acid (FFA), as the ability of insulin to inhibit lipolysis is impaired (29). In turn, increased concentrations of non-esterified fatty acids released by expanded VAT negatively affects the insulin signaling cascade $(30,31)$. Insulin resistance also causes reduced glucose transport into adipocytes, which may inhibit glycerol synthesis and impair re-esterification of FFA into triglycerides (32).

In the current study, TNF $\alpha$ and IL6 gene expression was observed to significantly increase in VAT in HFD-induced diabetes of KKAy mice, while following supplementing with EPS, the pro-inflammatory cytokines were markedly reduced. The results showed that EPS may alleviate the inflammatory condition in VAT. Similarly, in the HFD-induced diabetes of KKAy mice, ATGL and HSL gene expression was observed to be significantly increased. This increase meant a higher lipolysis in VAT resulting from insulin resistance. However, EPS supplementation decreased the gene expression of the two lipolytic enzymes. This may result from alleviation of inflammation in the VAT.

SirT1 and AMPK, as metabolic sensors, in conjunction with PGC-1 $\alpha$, are crucial links in a regulatory network for nutrient metabolic homeostasis (33). Since chronic overnutrition leads to subclinical inflammation, which is a characteristic of obesity and type 2 diabetes (25), there has been considerable interest in the role of AMPK and SirT1 involved in obesity-associated inflammation. Mounting evidence has suggested that AMPK and SirT1 have anti-inflammatory effects in adipocytes (34-36). AMPK $\alpha 1$ antagonizes fatty acid-induced inflammation through SirT1 (37) and AMPK also mediates the inhibition of nuclear factor $(\mathrm{NF})-\kappa \mathrm{B}$ signaling through action on its other downstream targets of PGC-1 $\alpha$, p53 and forkhead box O factors (38). Activation of AMPK may inhibit the synthesis of pro-inflammatory cytokines, including IL6 and IL8 in adipocytes (39). AICAR, an activator of AMPK, was also observed to reduce TNF $\alpha$ and IL6 secretion in human subcutaneous adipose tissue cultured ex vivo (40). Reduction of adipose tissue SirT1 expression leads to ectopic inflammatory gene expression and overexpression of SirT1 prevents HFD-induced increases in adipose tissue inflammation (41).

In the present study, AMPK $\alpha 1-$ siRNA or SirT1-siRNA in 3T3-L1 adipocytes in vitro were used to determine the pathway by which EPS exerts its effects on inflammation. The results showed that IL6 and TNF $\alpha$ mRNA expression were significantly increased following induction by insulin, while IL6 and TNF $\alpha$ mRNA abundance exhibited no change following treatment with insulin and EPS. siRNA-mediated knockdown of SirT1 or AMPK $\alpha 1$ alone affected the effects of EPS on inflammation, but adipocytes showed a significant reduction in IL6 and TNF $\alpha$ gene expression compared with 3T3-L1 cells treated with insulin. These results demonstrated that EPS may alleviate adipocyte inflammation predominantly through the AMPK/SirT1 pathway. In addition, the glucose uptake and Glut4 expression were negatively associated with IL6 and TNF $\alpha$ abundance, which further proved that Glut4 expression is decreased in insulin-resistant states (32).

In conclusion, the current observations suggest that EPS possibly exerts its anti-diabetic effect by alleviating adipocyte inflammation via the AMPK/SirT1 pathway. EPS is composed of glucose, mannose and galactose with $\alpha$-configuration, pyranoside and more branches (14). The diversity of monosaccharide residues provide great flexibility in the accurate modulatory mechanism of various cell-cell interactions in higher organisms (42), which may be associated with its anti-inflammatory effects. In addition, selenium may partially exert anti-inflammatory effects, since the organic selenium compounds, including selenoproteins, has been hypothesized to play a preventive role in inflammatory diseases (9). Consequently, the future challenge may be to purify EPS and define the 3D structure of polysaccharides and the structure-function correlation. The present results suggest great potential for investigators to clarify the biological activities of polysaccharides and develop clinical application in the treatment of diabetes.

\section{Acknowledgements}

This study was financially supported by grants from the National Basic Research Program of China (grant no. 2012CB124705) and the Modern Agro-industry Technology Research System (no. CARS-36).

\section{References}

1. Wisse BE: The inflammatory syndrome: the role of adipose tissue cytokines in metabolic disorders linked to obesity. J Am Soc Nephrol 15: 2792-2800, 2004.

2. Shoelson SE, Herrero L and Naaz A: Obesity, inflammation, and insulin resistance. Gastroenterology 132: 2169-2180, 2007.

3. Samaras K, Botelho NK, Chisholm DJ and Lord RV: Subcutaneous and visceral adipose tissue gene expression of serum adipokines that predict type 2 diabetes. Obesity (Silver Spring) 18: 884-889, 2010.

4. Ooi VE and Liu F: Immunomodulation and anti-cancer activity of polysaccharide-protein complexes. Curr Med Chem 7: 715-729, 2000.

5. Na HS, Lim YJ, Yun YS, Kweon MN and Lee HC: Ginsan enhances humoral antibody response to orally delivered antigen. Immune Netw 10: 5-14, 2010.

6. Ni W, Zhang X, Wang B, Chen Y, Han H, Fan Y, Zhou Y and Tai G: Antitumor activities and immunomodulatory effects of ginseng neutral polysaccharides in combination with 5-fluorouracil. J Med Food 13: 270-277, 2010.

7. Ananthi S, Raghavendran HR, Sunil AG, Gayathri V, Ramakrishnan $\mathrm{G}$ and Vasanthi HR: In vitro antioxidant and in vivo anti-inflammatory potential of crude polysaccharide from Turbinaria ornata (Marine Brown Alga). Food Chem Toxicol 48: 187-192, 2010.

8. Fu J, Fu J, Yuan J, Zhang N, Gao B, Fu G, Tu Y and Zhang Y: Anti-diabetic activities of Acanthopanax senticosus polysaccharide (ASP) in combination with metformin. Int J Biol Macromol 50: 619-623, 2012.

9. Kaur R and Sandhu HS: In vivo changes in antioxidant system and protective role of selenium in chlorpyrifos-induced subchronic toxicity in bubalus bubalis. Environ Toxicol Pharmacol 26: 45-48, 2008.

10. Douillet C, Tabib A, Bost M, Accominotti M, Borson-Chazot F and Ciavatti M: A selenium supplement associated or not with vitamin E delays early renal lesions in experimental diabetes in rats. Proc Soc Exp Biol Med 211: 323-331, 1996. 
11. Wang F, Yang $\mathrm{H}$ and Wang Y: Structure characterization of a fucose-containing exopolysaccharide produced by Enterobacter cloacae Z0206. Carbohydr Polym 92: 503-509, 2013.

12. Jin M, Lu Z, Huang M, Wang Y and Wang Y: Effects of Se-enriched polysaccharides produced by Enterobacter cloacae Z0206 on alloxan-induced diabetic mice. Int J Biol Macromol 50: 348-352, 2012

13. Lu Z, Jin M, Huang M, Wang Y and Wang Y: Bioactivity of selenium-enriched exopolysaccharides produced by Enterobacter cloacae Z0206 in broilers. Carbohydr Polym 96 131-136, 2013

14. Xu CL, Wang YZ, Jin ML and Yang XQ: Preparation, characterization and immunomodulatory activity of selenium-enriched exopolysaccharide produced by bacterium Enterobacter cloacae Z0206. Bioresour Technol 100: 2095-2097, 2009.

15. Rigas DA and Osgood EE: Purification and properties of the phytohemagglutinin of Phaseolus vulgaris. J Biol Chem 212: 607-615, 1955.

16. Fasshauer M, Klein J, Lossner U and Paschke R: Interleukin (IL)-6 mRNA expression is stimulated by insulin, isoproterenol, tumour necrosis factor alpha, growth hormone, and IL-6 in 3T3-L1 adipocytes. Horm Metab Res 35: 147-152, 2003.

17. Yoshioka K, Takahashi H, Homma T, Saito M, Oh KB, Nemoto $\mathrm{Y}$ and Matsuoka H: A novel fluorescent derivative of glucose applicable to the assessment of glucose uptake activity of Escherichia coli. Biochim Biophys Acta 1289: 5-9, 1996.

18. Ball SW, Bailey JR, Stewart JM, Vogels CM and Westcott SA: A fluorescent compound for glucose uptake measurements in isolated rat cardiomyocytes. Can J Physiol Pharmacol 80: 205-209, 2002

19. Zou C, Wang Y and Shen Z: 2-NBDG as a fluorescent indicator for direct glucose uptake measurement. J Biochem Biophys Methods 64: 207-215, 2005.

20. Dandona P, Aljada A and Bandyopadhyay A: Inflammation: the link between insulin resistance, obesity and diabetes. Trends Immunol 25: 4-7, 2004.

21. Jin M, Lu Z, Huang M, Wang Y and Wang Y: Sulfated modification and antioxidant activity of exopolysaccahrides produced by Enterobacter cloacae Z0206. Int J Biol Macromol 48 607-612, 2011.

22. Bijland S, Mancini SJ and Salt IP: Role of AMP-activated protein kinase in adipose tissue metabolism and inflammation. Clin Sci (Lond) 124: 491-507, 2013

23. Esposito K, Nappo F, Marfella R, Giugliano G, Giugliano F, Ciotola M, Quagliaro L, Ceriello A and Giugliano D: Inflammatory cytokine concentrations are acutely increased by hyperglycemia in humans: role of oxidative stress. Circulation 106: 2067-2072, 2002.

24. Mohanty P, Hamouda W, Garg R, Aljada A, Ghanim H and Dandona P: Glucose challenge stimulates reactive oxygen species (ROS) generation by leucocytes. J Clin Endocrinol Metab 85: 2970-2973, 2000.

25. Glass CK and Olefsky JM: Inflammation and lipid signaling in the etiology of insulin resistance. Cell Metab 15: 635-645, 2012.

26. Zhang W, Zhang X, Wang H, Guo X, Li H, Wang Y, Xu X, Tan L, Mashek MT, Zhang C, Chen Y, Mashek DG, Foretz M, Zhu C, Zhou H, Liu X, Viollet B, Wu C and Huo Y: AMP-activated protein kinase $\alpha 1$ protects against diet-induced insulin resistance and obesity. Diabetes 61: 3114-3125, 2012.

27. Fontana L, Eagon JC, Trujillo ME, Scherer PE and Klein S: Visceral fat adipokine secretion is associated with systemic inflammation in obese humans. Diabetes 56: 1010-1013, 2007.
28. Winkler G, Kiss S, Keszthelyi L, Sápi Z, Ory I, Salamon F, Kovács M, Vargha P, Szekeres O, Speer G, Karádi I, Sikter M, Kaszás E, Dworak O, Gerö G and Cseh K: Expression of tumor necrosis factor (TNF)-alpha protein in the subcutaneous and visceral adipose tissue in correlation with adipocyte cell volume, serum TNF-alpha, soluble serum TNF-receptor- 2 concentrations and C-peptide level. Eur J Endocrinol 149: 129-135, 2003.

29. Groop LC, Saloranta C, Shank M, Bonadonna RC, Ferrannini E and DeFronzo RA: The role of free fatty acid metabolism in the pathogenesis of insulin resistance in obesity and noninsulin-dependent diabetes mellitus. J Clin Endocrinol Metab 72: 96-107, 1991.

30. Ravussin E and Smith SR: Increased fat intake, impaired fat oxidation, and failure of fat cell proliferation result in ectopic fat storage, insulin resistance, and type 2 diabetes mellitus. Ann N Y Acad Sci 967: 363-378, 2002.

31. Rajala MW and Scherer PE: Minireview: the adipocyte - at the crossroads of energy homeostasis, inflammation, and atherosclerosis. Endocrinology 144: 3765-3773, 2003.

32. Abel ED, Peroni O, Kim JK, Kim YB, Boss O, Hadro E, Minnemann T, Shulman GI and Kahn BB: Adipose-selective targeting of the GLUT4 gene impairs insulin action in muscle and liver. Nature 409: 729-733, 2001.

33. Cantó C and Auwerx J: PGC-1alpha, SIRT1 and AMPK, an energy sensing network that controls energy expenditure. Curr Opin Lipidol 20: 98-105, 2009.

34. Salt IP and Palmer TM: Exploiting the anti-inflammatory effects of AMP-activated protein kinase activation. Expert Opin Investig Drugs 21: 1155-1167, 2012.

35. Yeung F, Hoberg JE, Ramsey CS, Keller MD, Jones DR, Frye RA and Mayo MW: Modulation of NF-kappaB-dependent transcription and cell survival by the SIRT1 deacetylase. EMBO J 23: 2369-2380, 2004.

36. Ghosh HS, Spencer JV, Ng B, McBurney MW and Robbins PD: Sirtl interacts with transducin-like enhancer of split-1 to inhibit nuclear factor kappaB-mediated transcription. Biochem J 408: 105-111, 2007.

37. Yang Z, Kahn BB, Shi H and Xue BZ: Macrophage alphal AMP-activated protein kinase (alpha1AMPK) antagonizes fatty acid-induced inflammation through SIRT1. J Biol Chem 285: 19051-19059, 2010.

38. Salminen A, Hyttinen JM and Kaarniranta K: AMP-activated protein kinase inhibits NF- $\kappa \mathrm{B}$ signaling and inflammation: impact on healthspan and lifespan. J Mol Med (Berl) 89: 667-676, 2011.

39. Lihn AS, Pedersen SB, Lund S and Richelsen B: The anti-diabetic AMPK activator AICAR reduces IL- 6 and IL- 8 in human adipose tissue and skeletal muscle cells. Mol Cell Endocrinol 292: 36-41, 2008.

40. Lihn AS, Jessen N, Pedersen SB, Lund S and Richelsen B: AICAR stimulates adiponectin and inhibits cytokines in adipose tissue. Biochem Biophys Res Commun 316: 853-858, 2004.

41. Gillum MP, Kotas ME, Erion DM, Kursawe R, Chatterjee P, Nead KT, Muise ES, Hsiao JJ, Frederick DW, Yonemitsu S, Banks AS, Qiang L, Bhanot S, Olefsky JM, Sears DD, Caprio S and Shulman GI: SirT1 regulates adipose tissue inflammation. Diabetes 60: 3235-3245, 2011.

42. Zhang M, Cui SW, Cheung PCK and Wang Q: Antitumor polysaccharides from mushrooms: a review on their isolation process, structural characteristics and antitumor activity. Trends Food Sci Tech 12: 4-19, 2008 